\title{
Integrated analysis of gene expression and DNA methylation profiles in ovarian cancer
}

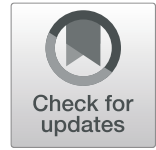

Guanghui Gong ${ }^{1,2^{*}}$, Ting Lin ${ }^{3,4}$ and Yishu Yuan ${ }^{1}$

\begin{abstract}
Background: Ovarian cancer is an epithelial malignancy that intrigues people for its poor outcome and lack of efficient treatment, while methylation is an important mechanism that have been recognized in many malignancies. In this study, we attempt to assess abnormally methylated gene markers and pathways in ovarian cancer by integrating three microarray datasets.

Methods: Three datasets including expression (GSE26712 and GSE66957) and methylation (GSE81224) datasets were accessed. GEO2R platform was used to detect abnormally methylated-differentially expressed genes. Proteinprotein interaction (PPI) networks were built and analysed for hypermethylated and hypermethylated differentially expressed genes using Cytoscape software and Mcode app. GEPIA and cBioPortal platforms were used to validate the expression of the hub genes and the correlation between their mRNA expressions and methylation levels. Kaplan Meier-plotter platform were used to assess the prognostic significance of the hub genes.

Results: Six hundred eighty-one hypomethylated-upregulated genes were detected and involved in Rap1 signaling pathway, biosynthesis of amino acids, endocrine resistance, apoptosis, pathways in cancer. The hub genes were TNF, UBC, SRC, ESR1, CDK1, PECAM1, CXCR4, MUC1, IKBKG. Additionally, 337 hypermethylated-downregulated genes were detected and involved in pathways in cancer, focal adhesion, sphingolipid signaling pathway, EGFR tyrosine kinase inhibitor resistance, cellular senescence. The hub genes were BDNF, CDC42, CD44, PPP2R5C, PTEN, UBB, BMP2, FOXO1, KLHL2. TNF, ESR1, MUC1, CD44, PPP2R5C, PTEN, UBB and FOXO1 showed significant negative correlation between their mRNA expressions and methylation levels. TNF, ESR1 and FOXO1 showed prognostic significance.
\end{abstract}

Conclusions: Two novel gene networks were found for ovarian cancer. TNF, ESR1, MUC1 and FOXO1 are our candidate genes that might take part in ovarian cancer progression in an epigenetic approach, TNF, ESR1 and FOXO1 may serve as potential markers for ovarian cancer prognosis evaluation.

Keywords: Ovarian cancer, Methylation, Gene expression

\footnotetext{
* Correspondence: gongguanghui@csu.edu.cn

${ }^{1}$ Department of Pathology, Xiangya Hospital, Central South University, 87

Xiangya Road, Changsha, Hunan 410008, People's Republic of China

${ }^{2}$ Institute of Reproductive and Stem Cell Engineering, School of Basic

Medical Science, Central South University, Changsha 410078, People's

Republic of China

Full list of author information is available at the end of the article
}

(c) The Author(s). 2020 Open Access This article is licensed under a Creative Commons Attribution 4.0 International License, which permits use, sharing, adaptation, distribution and reproduction in any medium or format, as long as you give appropriate credit to the original author(s) and the source, provide a link to the Creative Commons licence, and indicate if changes were made. The images or other third party material in this article are included in the article's Creative Commons licence, unless indicated otherwise in a credit line to the material. If material is not included in the article's Creative Commons licence and your intended use is not permitted by statutory regulation or exceeds the permitted use, you will need to obtain permission directly from the copyright holder. To view a copy of this licence, visit http://creativecommons.org/licenses/by/4.0/ The Creative Commons Public Domain Dedication waiver (http://creativecommons.org/publicdomain/zero/1.0/) applies to the data made available in this article, unless otherwise stated in a credit line to the data. 


\section{Background}

Ovarian cancer, an epithelial malignancy, is reported to be the most common lethal malignancy among gynecologic cancer [1]. And the outcome of the patients is poor due to late diagnosis for lack of early signs and symptoms [2]. Ovarian cancer is prone to metastasis and recurrence [3], but the pathogenesis is still unclear, the suspected etiology include ovulation, hormones, genetics, environmental factors [4-6].

The standard treatment for ovarian cancer include surgery and chemotherapy, other treatments include radiation, hormone, immunotherapy, but the survival rate for it is still low (https://www.cancerresearchuk.org/ about-cancer/ovarian-cancer/survival) due to advanced stage when diagnosed and frequent recurrence (which often accompanied with increases chemoresistance) [5], thus more attention should be paid to ovarian cancer.

DNA methylation, the most studied epigenetic mechanism, is reported to be related to mRNA and miRNA expression regulation, thus contribute to cancer initiation or progression [7]. Recently, more and more studies indicated that abnormal gene methylation in promoter regions is involved with chemical therapy and targeting therapy of ovarian cancer [8-10].

In this study, DNA methylation datasets in ovarian cancer were screened. A series of bioinformatics tools were used for integrated analysis and detection of hub genes. Then the levels of hub genes, and the correlation between their expression and methylation level of them were confirmed by GEPIA [11], and cBioPortal [12, 13] platforms, with the data from The Cancer Genome Atlas (TCGA) and GTEx (The Genotype-Tissue Expression). These confirmed genes are our candidate genes for a deeper study later on in ovarian cancer progress.

\section{Methods}

Gene datasets and differentially expressed genes identification

Gene expression datasets: GSE26712 (185 ovarian cancer samples, 10 normal samples), GSE66957 (57 ovarian cancer samples, 12 normal samples) and gene methylation datasets: GSE81224 (10 ovarian cancer samples, 5 normal samples) were screened from Gene Expression Omnibus (GEO) database (http://www.ncbi.nlm.nih.gov/ geo/) for the biggest number of cases and the data provided are normalized that no further adjustment is needed. GEO2R platform were used to detect differentially expressed genes (DEGs) and abnormally methylated genes between normal and ovarian cancer samples. The parameter for DEGs and abnormally methylated genes were set with $|t|>2, P<0.05$. Then the DEGs and abnormally methylated genes were processed in Funrich software (http://www.funrich.org) for integrated analysis and Venn diagram visualization.

\section{PPI network construction and modular analysis}

STRING was used to build the protein-protein interaction (PPI) network (https://string-db.org/) [14], with minimum required interaction score set in 0.4 . The result data was imported into Cytoscape [15] for visualization, subsequently, app Mcode (i.e., Molecular Complex Detection) was used to perform module analysis (Node score cut off $>3.5$ ) for the PPI network complex. Hub genes were determined by connectivity degree $>27$ for the hypomethylated-upregulated (HOUP) genes and connectivity degree $>12$ for the hypermethylateddownregulated (HEDW) genes, the calculation of connection degrees of genes was performed using Microsoft Office Excel.

\section{GO and Reactome, KEGG pathway enrichment analysis}

The STRING website described above also helped in the integrated analysis of biological meaning of the proteins (or genes), Gene Ontology (GO) analysis (including the biological process (BP), cellular component (CC), and molecular function (MF)), Reactome pathway and the Kyoto Encyclopedia of Genes and Genomes (KEGG) pathway enrichment analysis were conducted for the selected genes, $P$ value $<0.05$ was considered statistically significant, and top 10 of BP, CC, MF items and top 5 of KEGG, Reactome pathways were illustrated using a web tool (http://www.ehbio.com/ImageGP/index.php/Home/ Index/index.html).

\section{Validation of the expression of hub genes and correlations between methylation and mRNA levels in TCGA samples}

GEPIA platform was used to validate the expression levels of the hub genes and $|\log 2 \mathrm{FC}|>1$ and $P$ value < 0.05 was considered statistically significant. Methylation data TCGA $27 \mathrm{k}$ methylation data were selected to assess the correlations between methylation levels and corresponding mRNA levels using cBioPortal platform (TCGA $450 \mathrm{k}$ methylation data were not chosen because it contains only10 cases).

\section{Prognostic analysis of hub genes in ovarian cancer tissue samples}

The overall survival (OS), progression-free survival (PFS) and post progression survival (PPS) curves of each hub gene were drawn using the online platform, the Kaplan Meier-plotter (http://kmplot.com/analysis/index.php) [16]. Both logrank $P$ value and Hazard Ratio (HR, and 95\% confidence intervals) were evaluated, $P<0.05$ was considered statistically significant. 


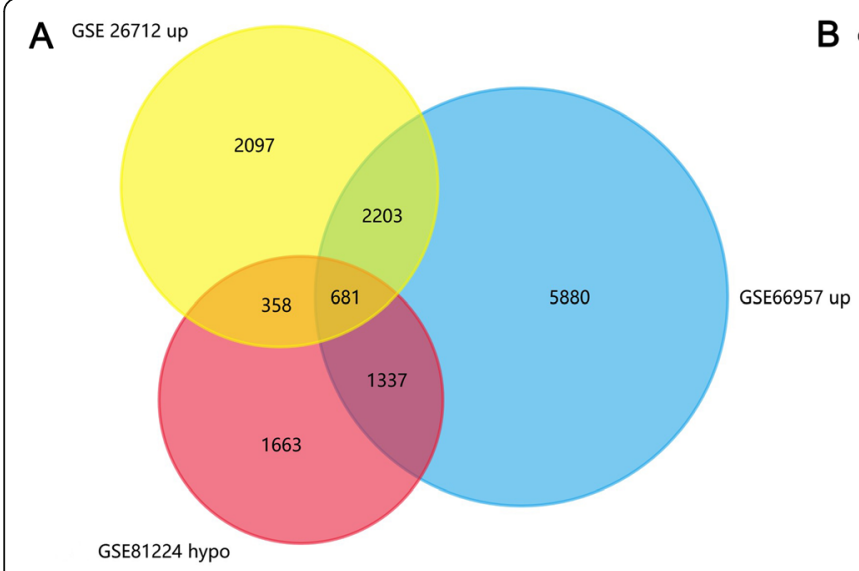

B GSE66957 down

Fig. 1 The integrated analysis of abnormal DNA methylation genes in ovarian cancer. The gene counting numbers were summarized in gene expression datasets (GSE26712, GSE66957) and gene methylation dataset (GSE81224), respectively. Left panel (a) was represented the hypomethylation and up-regulated genes, while right panel (b) represented the hypermethylation and down-regulated genes

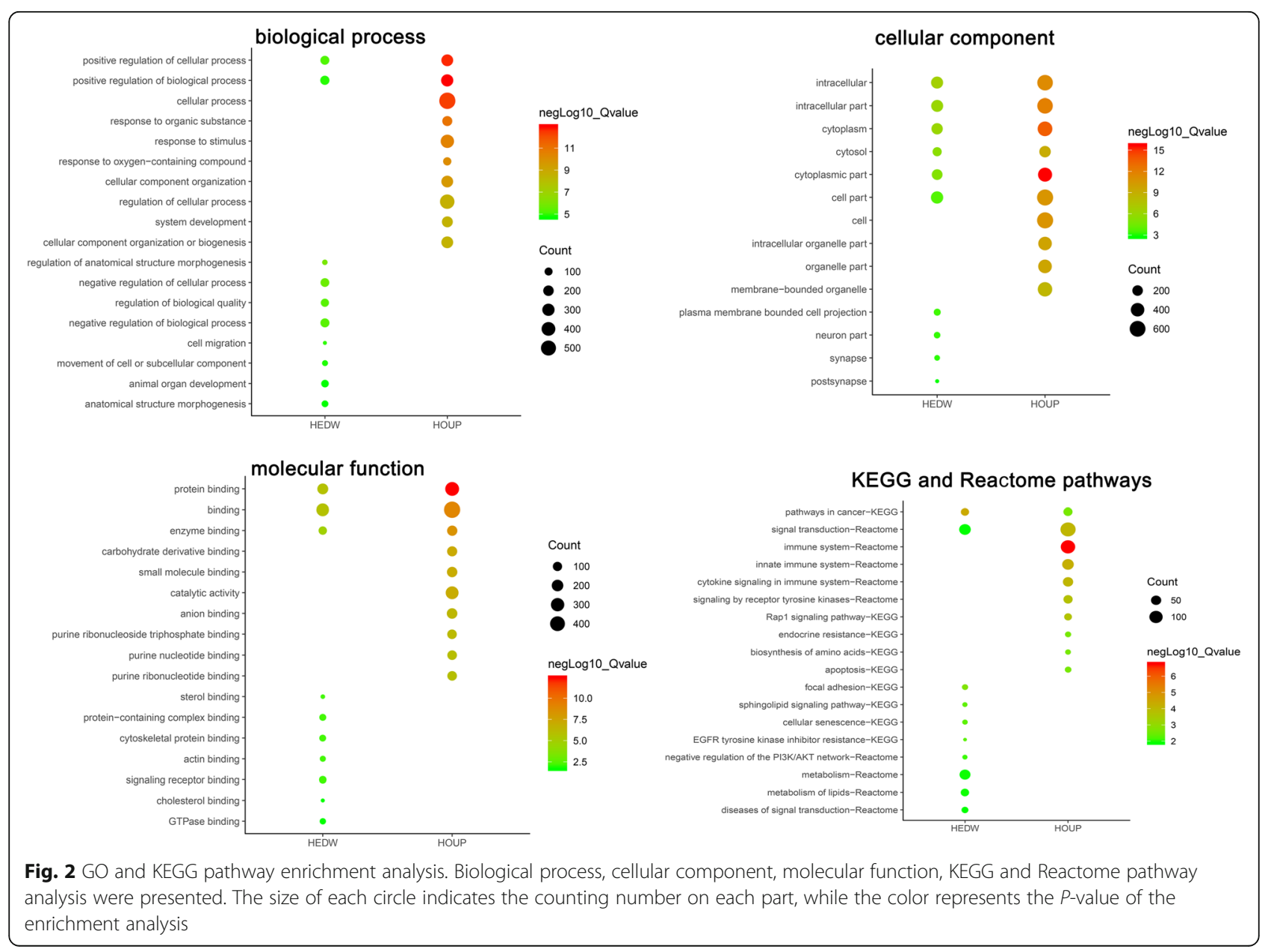




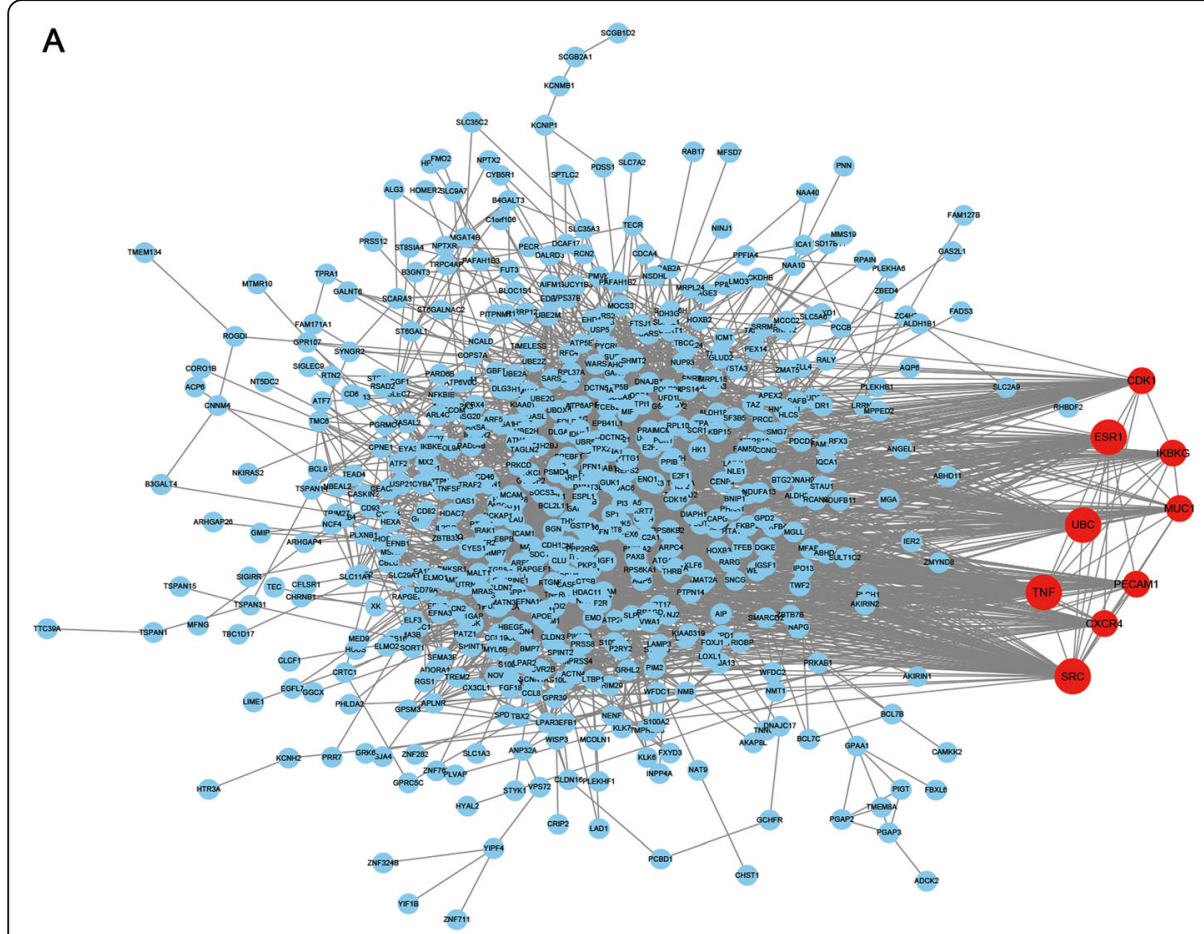

B

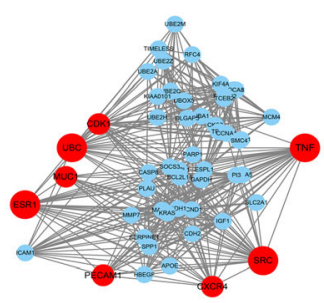

C

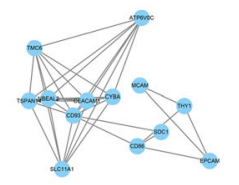

Fig. 3 Protein-protein interaction (PPI) network and top three modules of the HOUP genes. a The PPI networks. The size of node indicated the connection degree value. Dark nodes represented hub genes. b-d Module 1 consists of 53 nodes, module 2 consists of 13 nodes and module 3 consists of 51 nodes

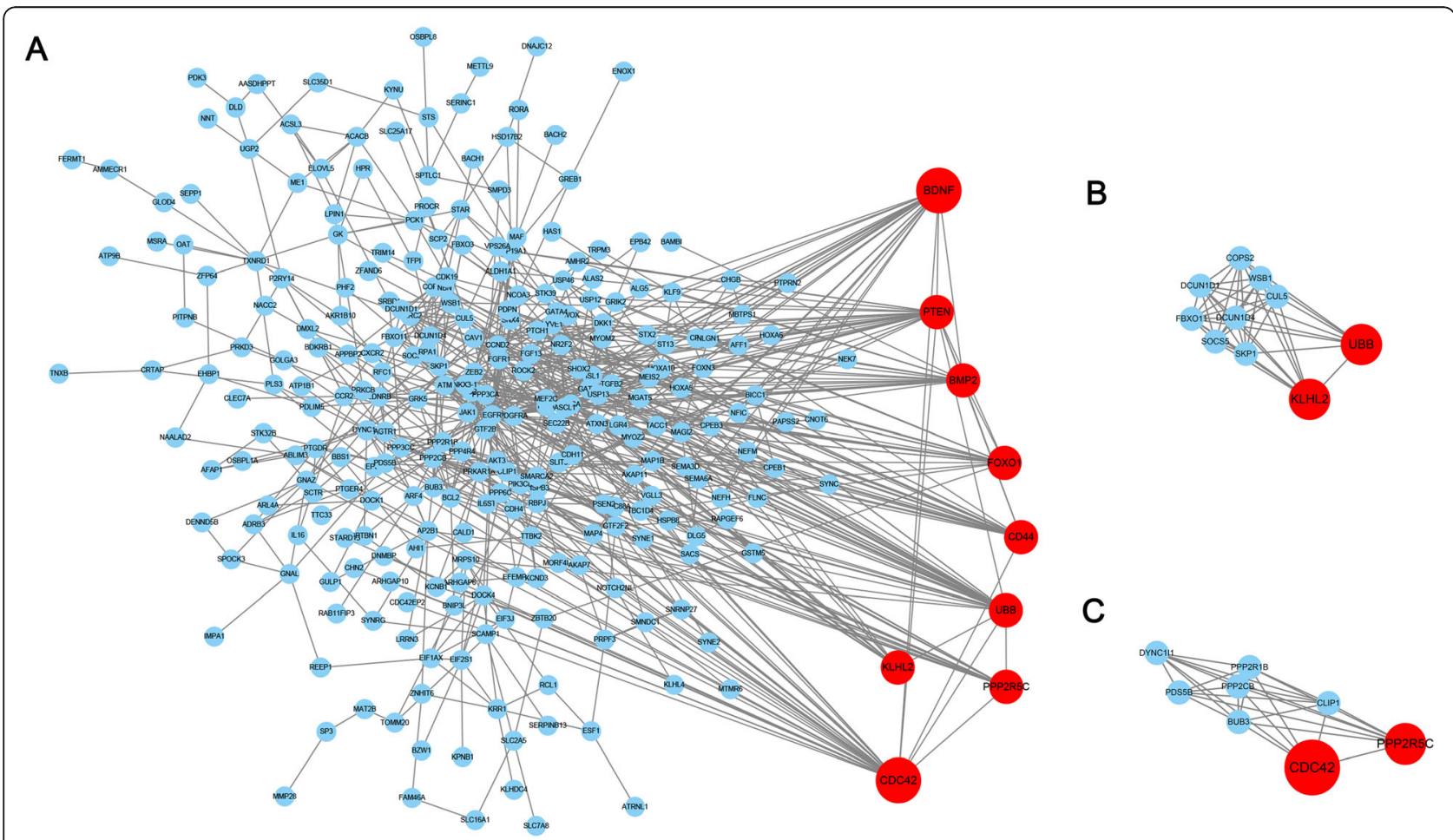

Fig. 4 Protein-protein interaction (PPI) network and top three modules of the HEDW genes. a The PPI networks. The size of node indicated the connection degree value. Dark nodes represented hub genes. b-c Module 1 consists of 10 nodes and module 2 consists of 8 nodes 


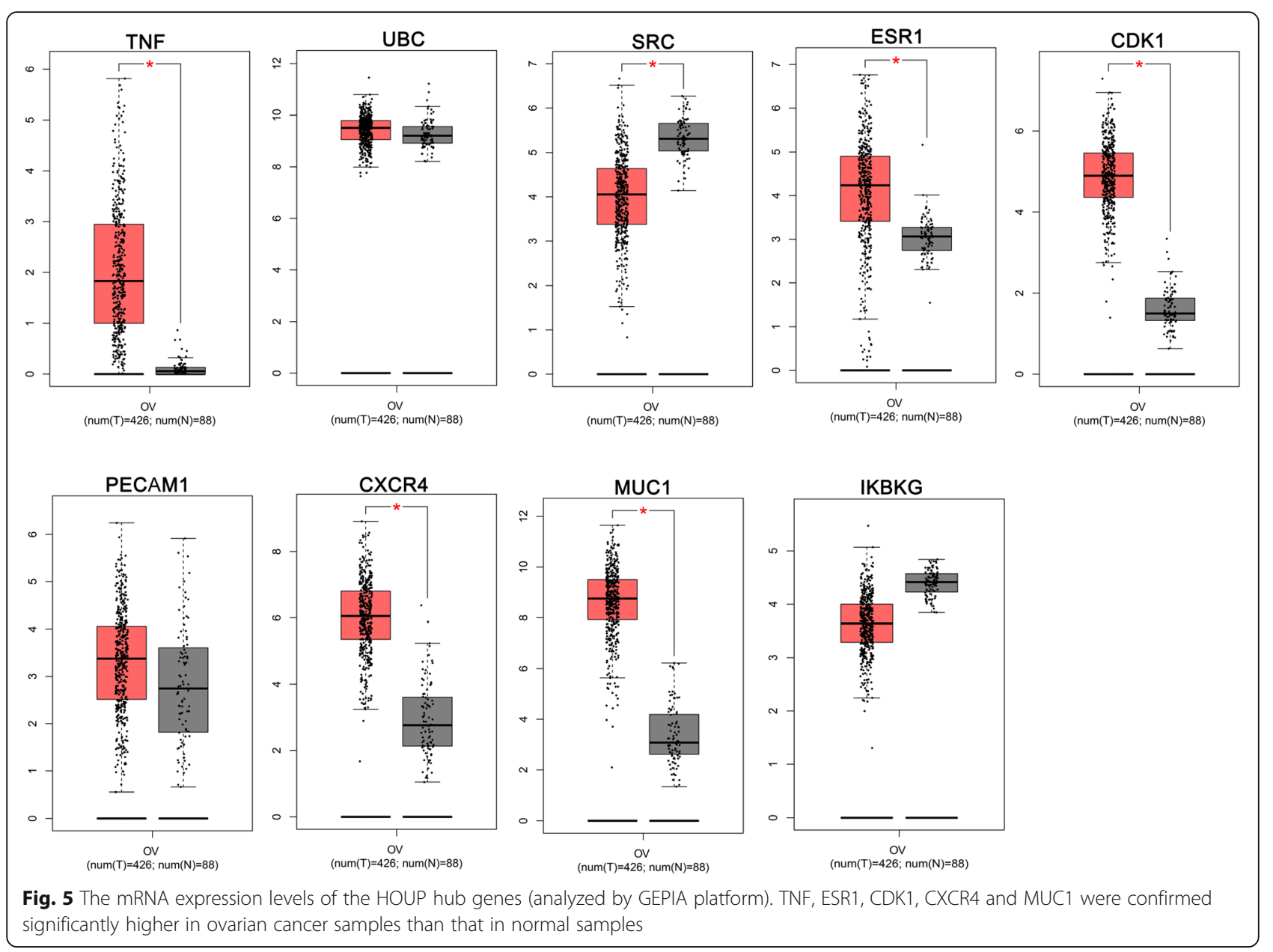

\section{Results}

Detection of abnormal methylated-differentially expressed genes in ovarian cancer

GSE26712 and GSE66957 (expression datasets) and GSE81224 (methylation datasets) were analyzed with GEO2R, two Veen diagrams were drawn and 681 HOUP genes and 337 HEDW genes were detected from these three datasets (Fig. 1).

\section{Biological function and pathways enrichment analysis}

The HOUP and HEDW genes were imported into STRING, respectively. Biological classification was evaluated for the two lists of genes including GO term enrichment analysis, KEGG pathways and Reactome pathways enrichment analysis.

The HOUP genes were enriched in biological process such as positive regulation of biological process, positive regulation of cellular process, cellular process, response to organic substance, response to stimulus. GO cell component analysis showed that the genes were significantly enriched in cytoplasmic part, cytoplasm, intracellular part, intracellular, cell. GO molecular function analysis showed significantly enrichment in.

protein binding, binding, enzyme binding, carbohydrate derivative binding, catalytic activity. KEGG and Reactome pathways analysis indicated enrichment in Rap1 signaling pathway, biosynthesis of amino acids, endocrine resistance, apoptosis, pathways in cancer, immune system, innate immune system, cytokine signaling in immune system, signal transduction, signaling by receptor tyrosine kinases (Fig. 2).

The HEDW genes were enriched in biological process such as regulation of anatomical structure morphogenesis, negative regulation of cellular process, negative regulation of biological process, regulation of biological quality, positive regulation of cellular process. GO cell component analysis showed that the genes were significantly enriched in intracellular, cytoplasm, intracellular part, cytosol, cytoplasmic part. GO molecular function analysis showed significantly enrichment in binding, protein binding, enzyme binding, actin binding, cytoskeletal protein binding. KEGG and Reactome pathways analysis indicated enrichment in pathways in cancer, focal 


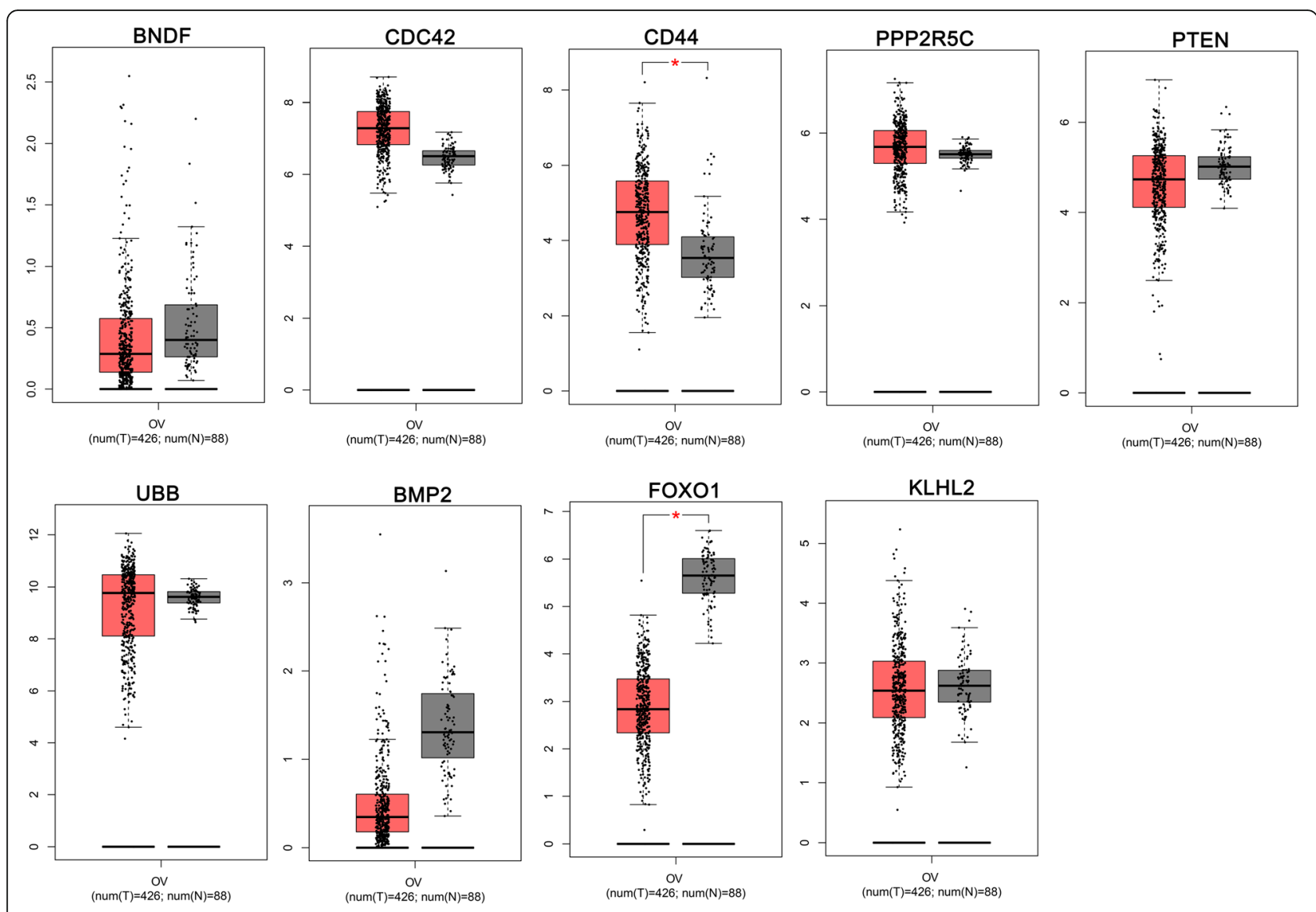

Fig. 6 The mRNA expression levels of the HEDW hub genes (analyzed by GEPIA platform). FOXO1 was significantly lower in ovarian cancer tissues than that in normal tissues

adhesion, sphingolipid signaling pathway, EGFR tyrosine kinase inhibitor resistance, cellular senescence, negative regulation of the PI3K/AKT network, metabolism, metabolism of lipids, signal transduction, diseases of signal transduction (Fig. 2).

\section{PPI networks and module analysis}

The PPI network graph for the HOUP genes was illustrated in Fig. 3a, 677 nodes and 3349 edges were included in the network. Nine nodes with the highest connectivity degrees were judged as hub genes, including tumor necrosis factor (TNF), polyubiquitin-C (UBC), proto-oncogene tyrosine-protein kinase (SRC), estrogen receptor 1 (ESR1), Cyclin-dependent kinase 1 (CDK1), platelet endothelial cell adhesion molecule (PECAM1), C-X-C chemokine receptor type 4 (CXCR4), mucin-1.

(MUC1), inhibitor of nuclear factor kappa B kinase regulatory subunit gamma (IKBKG). Three significant modules (Fig. 3b-d) were detected using app Mcode. Function analysis of the top three module genes using STRING showed enrichment in positive regulation of nitrogen compound metabolic process, positive regulation of macromolecule metabolic process, positive regulation of cellular metabolic process, positive regulation of cellular protein metabolic process, regulation of cellular process.

The PPI network graph for the HEDW genes was illustrated in Fig. 4a, 334 nodes and 772 edges were included in the network. Nine nodes with the highest connectivity degrees were judged as hub genes, including brain-derived neurotrophic factor (BDNF), cell division control protein 42 homolog (CDC42), CD44 antigen (CD44), Serine/threonine-protein phosphatase $2 \mathrm{~A} 56 \mathrm{kDa}$ regulatory subunit gamma isoform (PPP2R5C), phosphatase and Tensin homolog (PTEN), polyubiquitin-B (UBB), bone morphogenetic protein 2 (BMP2), forkhead box protein O1 (FOXO1), Kelchlike protein 2 (KLHL2). Two significant modules (Fig. $4 \mathrm{~b}-\mathrm{c}$ ) were detected by app Mcode. Function analysis showed enrichment in protein modification by small protein conjugation, post-translational protein modification, protein ubiquitination, protein polyubiquitination, mitotic cell cycle. 
Table 1 Methylation analysis of hub genes in TCGA ovarian cancer. Negative correlations were found between TNF, ESR1, MUC1, CD44, PPP2R5C, PTEN, UBB and FOXO1 mRNA levels and methylation levels

\begin{tabular}{|c|c|}
\hline Gene & correlations of methylation level and mRNA level (cBioportal) \\
\hline \multirow[t]{2}{*}{ TNF } & Spearman: $-0.38(p=2.16 \mathrm{e}-18)$ \\
\hline & Pearson: $-0.38(p=7.38 \mathrm{e}-18)$ \\
\hline \multirow[t]{2}{*}{ UBC } & Spearman: $0.01(p=0.799)$ \\
\hline & Pearson: $0.04(p=0.353)$ \\
\hline SRC & No data \\
\hline \multirow[t]{2}{*}{ ESR1 } & Spearman: $-0.24(p=1.13 \mathrm{e}-7)$ \\
\hline & Pearson: $-0.24(p=1.04 \mathrm{e}-7)$ \\
\hline CDK1 & No data \\
\hline PECAM1 & No data \\
\hline \multirow[t]{2}{*}{ CXCR4 } & Spearman: $-0.05(p=0.263)$ \\
\hline & Pearson: $-0.05(p=0.257)$ \\
\hline \multirow[t]{2}{*}{ MUC1 } & Spearman: $-0.13(p=3.288 \mathrm{e}-3)$ \\
\hline & Pearson: $-0.34(p=9.48 \mathrm{e}-15)$ \\
\hline IKBKG & No data \\
\hline \multirow[t]{2}{*}{ BDNF } & Spearman: $-0.04(p=0.435)$ \\
\hline & Pearson: $0.03(p=0.516)$ \\
\hline \multirow[t]{2}{*}{$\mathrm{CDC} 42$} & Spearman: $-0.09(p=0.0469)$ \\
\hline & Pearson: $-0.08(p=0.0702)$ \\
\hline \multirow[t]{2}{*}{ CD44 } & Spearman: $-0.22(p=5.88 \mathrm{e}-7)$ \\
\hline & Pearson: $-0.22(p=8.34 \mathrm{e}-7)$ \\
\hline \multirow[t]{2}{*}{ PPP2R5C } & Spearman: $-0.20(p=1.194 \mathrm{e}-5)$ \\
\hline & Pearson: $-0.13(p=4.291 \mathrm{e}-3)$ \\
\hline \multirow[t]{2}{*}{ PTEN } & Spearman: $-0.18(p=5.541 \mathrm{e}-5)$ \\
\hline & Pearson: $-0.23(p=3.32 \mathrm{e}-7)$ \\
\hline \multirow[t]{2}{*}{ UBB } & Spearman: $-0.69(p=6.66 \mathrm{e}-70)$ \\
\hline & Pearson: $-0.81(p=1.76 \mathrm{e}-116)$ \\
\hline \multirow[t]{2}{*}{ BMP2 } & Spearman: $-0.00(p=0.944)$ \\
\hline & Pearson: $-0.11(p=0.0150)$ \\
\hline \multirow[t]{2}{*}{ FOXO1 } & Spearman: $-0.16(p=4.634 \mathrm{e}-4)$ \\
\hline & Pearson: $-0.17(p=1.385 e-4)$ \\
\hline KLHL2 & No data \\
\hline
\end{tabular}

The validation of hub genes expression levels in TCGA ovarian cancer samples

To validate the expression levels of the HOUP and HEDW hub genes, GEPIA platform was used with the data origin from TCGA and GTEx. The results of the HOUP hub genes confirmed that the expression levels of TNF, ESR1, CDK1, CXCR4 and MUC1 (Fig. 5), indicating these 5 hypomethylated genes were activated in ovarian cancer development. For the HEDW hub genes, FOXO1 was significantly lower in ovarian cancer tissues than that in normal tissues (Fig. 6), indicating it might participate in ovarian cancer development with a different approach.

\section{Methylation level and mRNA expression level correlation analysis of the hub genes in ovarian cancer \\ For further validation of the effect of methylation on mRNA expression, we performed a correlation analysis for the two lists of hub genes with cBioPortal, negative correlations were found in TNF, ESR1, MUC1, CD44, PPP2R5C, PTEN, UBB and FOXO1 (Table 1) between DNA methylation levels and corresponding mRNA levels. \\ Taken together, TNF, ESR1, MUC1 and FOXO1 are selected as our candidate genes for further research.}

\section{The prognostic significance of validated hub genes in ovarian cancer}

To estimate the prognostic significance of abnormal expressed TNF, ESR1, MUC1 and FOXO1, the survival time (include OS, PFS and PPS) and gene expression levels were acquired from Kaplan Meier-plotter website. The analysis results showed that higher level of TNF is related to longer OS and PPS time (based on the survival curves and logrank $P$ value), and higher level of ESR1 and lower level of FOXO1 are potential protective factors for ovarian cancer patients' survival (based on the $\mathrm{HR}$ and $95 \%$ confidence intervals value) (Fig. 7). These three key genes may serve as potential markers for ovarian cancer prognosis evaluation.

\section{Discussion}

Ovarian cancer is fatal, with high rate of metastasis, drug resistance and recurrence. But the progression and treatment for it remains unsolved. Recent studies focus on its proliferation, migration, and invasion showed relevance with miRNAs [17-19], lncRNAs [20, 21], and EMT (epithelial-mesenchymal transition) [22]. And there are also studies focus on treatment for it, such as PARP inhibitors [23, 24], hyperthermic intraperitoneal chemotherapy [25] and nanotherapy, but until now, survival rate of ovarian cancer remains low. Inspiringly, more and more microarray were applied for the investigation of its progression and drug resistance [26, 27] presented us with massive information.

In our study, three datasets were used and 681 HOUP genes and 337 HEDW genes were identified. The HOUP genes were enriched in biological processes of positive regulation of biological process, positive regulation of cellular process, cellular process, response to organic substance, response to stimulus, it is reasonable. Cell component analysis for the HOUP genes showed enrichment in cytoplasmic part, cytoplasm, intracellular part, intracellular, cell. For molecular function, significant enrichment was found in protein binding, binding, enzyme 


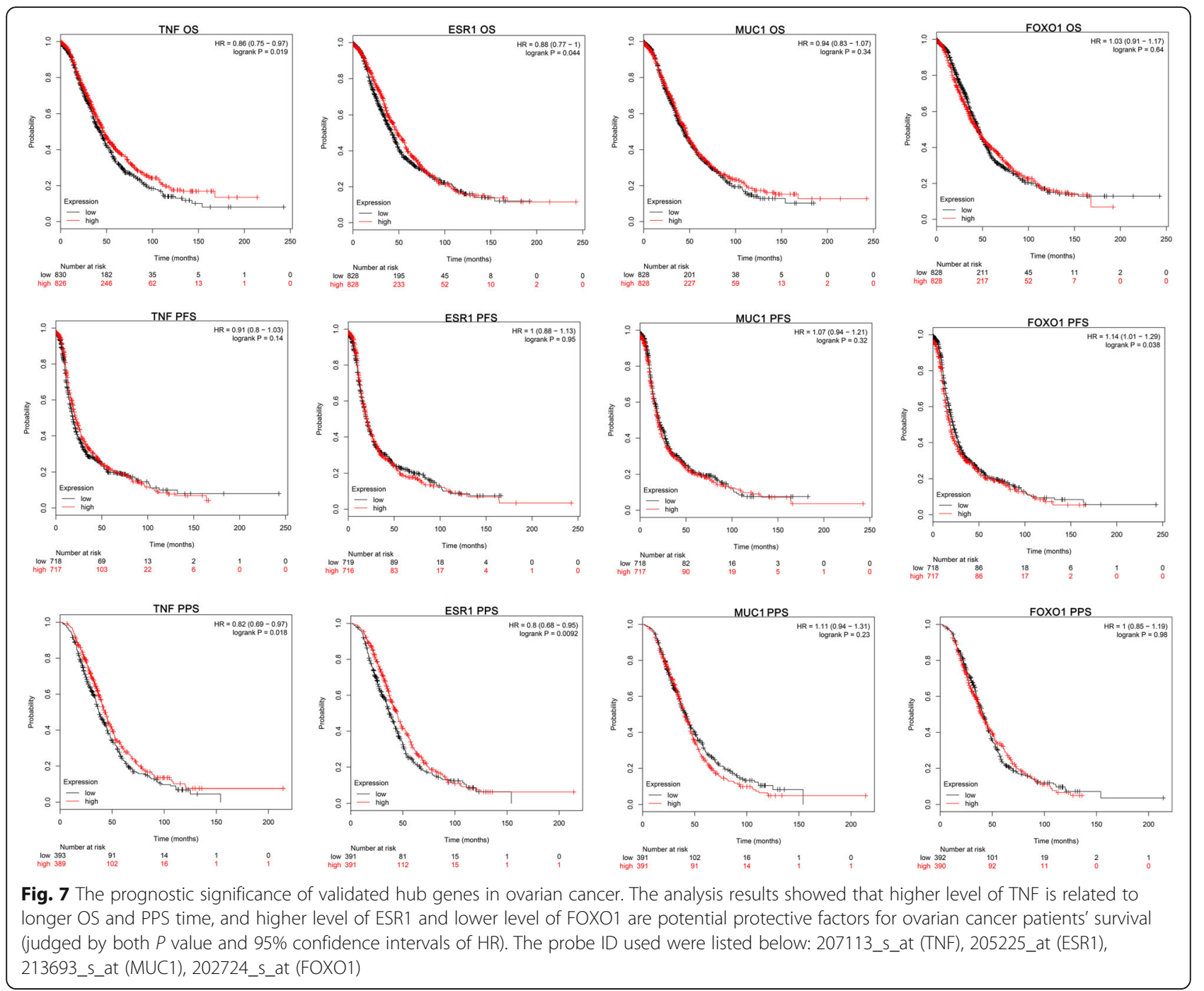

binding, carbohydrate derivative binding, catalytic activity. The analysis is also reasonable because material and energy metabolism and protein binding are common activities in tumor cells including ovarian cancer. KEGG pathways analysis for the HOUP genes showed enrichment in Rap1 signaling pathway, biosynthesis of amino acids, endocrine resistance, apoptosis, pathways in cancer, immune system, innate immune system, cytokine signaling in immune system, signal transduction, signaling by receptor tyrosine kinases. It is also reasonable because immune, cytokine, biosynthesis, apoptosis in accordance with the nature of cancer. KEGG pathways analysis for the HEDW genes showed enrichment in pathways in cancer, focal adhesion, sphingolipid signaling pathway, EGFR tyrosine kinase inhibitor resistance, cellular senescence, negative regulation of the PI3K/ AKT network, metabolism, metabolism of lipids, signal transduction, diseases of signal transduction. Related studies about sphingolipid [28], EGFR tyrosine kinase inhibitor [29], cellular senescence [30], PI3K/AKT network [31] and metabolism of lipids [32] in ovarian cancer were found. In summary, our biological analysis results were logical and in accordance with previous researches.

GEPIA platform were used to validate of the mRNA expression of 9 HOUP hub genes, named TNF, UBC, SRC, ESR1, CDK1, PECAM1, CXCR4, MUC1 and IKBKG, with data from TCGA and GTEx, TNF, ESR1, CDK1, CXCR4 and MUC1 were confirmed significantly higher in ovarian cancer samples than that in normal samples. To test whether DNA hypomethylation caused abnormal high expression, we explored the cBioPortal platform, and TNF, ESR1, MUC1 were confirmed with negative correlations with mRNA levels (Table 1). The mRNA expression of 9 HEDW hub genes, i.e., BDNF, CDC42, CD44, PPP2R5C, PTEN, UBB, BMP2, FOXO1, KLHL2, were also validated using GEPIA. FOXO1 was 
significantly lower in ovarian cancer samples than that in normal samples. Then cBioPortal platform was used again, and FOXO1 were confirmed with negative correlation with their mRNA levels (Table 1).

TNF, ESR1, MUC1 are HOUP genes, suggesting a potential role in ovarian cancer progression. According to the literature, TNF is widely studied in a variety of cancers, including ovarian cancer, it is also a major mediator of inflammation, there are also report trying to combine its effect in inflammation and carcinogenesis [33, 34], while no report concerning methylation of TNF in ovarian cancer was found. ESR1, reported in many solid malignancies [35], is frequently methylated in ovarian cancer cell lines [36], its methylation was also detected in cfDNA of high-grade serous ovarian cancer patients [37]. High expression of MUC1 is associated with epithelial ovarian cancer progression [38], hypomethylated MUC1 in poorly-differentiated ovarian cancer indicated functions in tumorigenesis, metastasis, invasion and migration [39], and a combination of MUC1 vaccination and anti-PD-L1 blockade resulted improved survival in ovarian cancer patients [40].

FOXO1, a HEDW genes, effects in many carcinomas including ovarian cancer [41], it is also related to drug resistance in ovarian cancer [42, 43], while it is not reported in ovarian cancer concerning methylation of FOXO1.

\section{Conclusions}

Taken together, with the datasets of gene expression and methylation, our study presented an integrated bioinformatics analysis of abnormally methylated DEGs for ovarian cancer. Hub genes including TNF, ESR1, MUC1 and FOXO1 might be potential targets for diagnosis or treatment of ovarian cancer in an epigenetic approach, TNF, ESR1 and FOXO1 may serve as potential markers for ovarian cancer prognosis evaluation.

\section{Acknowledgements}

Not applicable.

\section{Ethics approval and consent to participation}

Not applicable.

\section{Author contributions}

GGH and LT conceived and designed the study, GGH analyzed the patient data, and was a major contributor in writing the manuscript, LT and YYS helped in writing and revising the manuscript. All authors read and approved the final manuscript.

\section{Funding}

None.

\section{Availability of data and materials}

The datasets analyzed during the current study are available in the GEO repository,

https://www.ncbi.nlm.nih.gov/geo/query/acc.cgi?acc=GSE26712 https://www.ncbi.nlm.nih.gov/geo/query/acc.cgi?acc=GSE66957 https://www.ncbi.n/m.nih.gov/geo/query/acc.cgi?acc=GSE81224
Consent for publication

Not applicable.

\section{Competing interests}

The authors declare that they have no competing interests.

\section{Author details}

${ }^{1}$ Department of Pathology, Xiangya Hospital, Central South University, 87 Xiangya Road, Changsha, Hunan 410008, People's Republic of China. ${ }^{2}$ Institute of Reproductive and Stem Cell Engineering, School of Basic Medical Science, Central South University, Changsha 410078, People's Republic of China. ${ }^{3}$ Hunan Provincial Key Laboratory for the Prevention and Treatment of Ophthalmology and Otolaryngology Diseases with Traditional Chinese Medicine, Changsha 410208, People's Republic of China. ${ }^{4}$ Hunan Provincial Key Discipline of Chinese Head and Neck Science, Changsha 410208, People's Republic of China.

Received: 30 August 2019 Accepted: 12 March 2020

Published online: 19 March 2020

\section{References}

1. Taylor KN, Eskander RN. PARP inhibitors in epithelial ovarian cancer. Recent Pat Anticancer Drug Discov. 2018;13(2):145-58.

2. Doubeni C, Doubeni A, Myers A. Diagnosis and Management of Ovarian Cancer. Am Fam Physician. 2016:93(11):937-44

3. Wang Y, Jiang J, He L, Gong G, Wu X. Effect of Lamin-a expression on migration and nuclear stability of ovarian cancer cells. Gynecol Oncol. 2019; 152(1):166-76.

4. Malani PN. Harrison's principles of internal medicine. JAMA. 2012;308(17): 1813-4.

5. Jayson GC, Kohn EC, Kitchener HC, Ledermann JA. Ovarian cancer. Lancet. 2014;384(9951):1376-88

6. Salehi F, Dunfield L, Phillips KP, Krewski D, Vanderhyden BC. Risk factors for ovarian cancer: an overview with emphasis on hormonal factors. J Toxicol Environ Health B Crit Rev. 2008;11(3-4):301-21.

7. Szigeti K, Galamb O, Kalmár A, Barták B, Nagy Z, Márkus E, et al. Role and alterations of DNA methylation during the aging and cancer. Orv Hetil. 2018;159(1):3-15.

8. Dai F, Zhang Y, Zhu X, Shan N, Chen Y. Anticancer role of MUC1 aptamermiR-29b chimera in epithelial ovarian carcinoma cells through regulation of PTEN methylation. Target Oncol. 2012;7(4):217-25.

9. Flanagan JM, Wilson A, Koo C, Masrour N, Gallon J, Loomis E, et al. Platinum-based chemotherapy induces methylation changes in blood DNA associated with overall survival in patients with ovarian cancer. Clin Cancer Res. 2017;23(9):2213-22.

10. Natanzon Y, Goode E, Cunningham J, editors. Epigenetics in ovarian cancer. Seminars in cancer biology; 2018: NIH Public Access.

11. Tang Z, Li C, Kang B, Gao G, Li C, Zhang Z. GEPIA: a web server for cancer and normal gene expression profiling and interactive analyses. Nucleic Acids Res. 2017;45(W1):W98-W102.

12. Gao J, Aksoy BA, Dogrusoz U, Dresdner G, Gross B, Sumer SO, et al. Integrative analysis of complex cancer genomics and clinical profiles using the cBioPortal. Sci Signal. 2013;6(269):pl1.

13. Cerami E, Gao J, Dogrusoz U, Gross B, Sumer S, Aksoy B, et al. The cBio cancer genomics portal: an open platform for exploring multidimensional cancer genomics data. Cancer Discov. 2012;2(5):401-4.

14. Szklarczyk D, Gable AL, Lyon D, Junge A, Wyder S, Huerta-Cepas J, et al. STRING V11: protein-protein association networks with increased coverage, supporting functional discovery in genome-wide experimental datasets. Nucleic Acids Res. 2018;47(D1):D607-D13.

15. Shannon P, Markiel A, Ozier O, Baliga NS, Wang JT, Ramage D, et al. Cytoscape: a software environment for integrated models of biomolecular interaction networks. Genome Res. 2003;13(11):2498-504.

16. Győrffy B, Lánczky A, Szállási Z. Implementing an online tool for genome-wide validation of survival-associated biomarkers in ovariancancer using microarray data from 1287 patients. Endocr Relat Cancer 2012;19(2):197-208

17. Wu Q, Ren X, Zhang Y, Fu X, Li Y, Peng Y, et al. MiR-221-3p targets ARF4 and inhibits the proliferation and migration of epithelial ovarian cancer cells. Biochem Biophys Res Commun. 2018;497(4):1162-70. 
18. Jiang B, Zhu S-J, Xiao S-S, Xue M. MiR-217 inhibits M2-like macrophage polarization by suppressing secretion of Interleukin-6 in ovarian Cancer. Inflammation. 2019;42(5):1517-29.

19. Xiao F, Li Y, Wan Y, Xue M. MircroRNA-139 sensitizes ovarian cancer cell to cisplatin-based chemotherapy through regulation of ATP7A/B. Cancer Chemother Pharmacol. 2018;81(5):935-47.

20. Chen P, Fang X, Xia B, Zhao Y, Li Q, Wu X. Long noncoding RNA LINC00152 promotes cell proliferation through competitively binding endogenous miR-125b with MCL-1 by regulating mitochondrial apoptosis pathways in ovarian cancer. Cancer Med. 2018;7(9):4530-41.

21. Ma J, Xue M. LINK-A IncRNA promotes migration and invasion of ovarian carcinoma cells by activating TGF- $\beta$ pathway. Biosci Rep. 2018;38(5). https:// doi.org/10.1042/BSR20180936.

22. Dong S, Wang $R$, Wang H, Ding Q, Zhou X, Wang J, et al. HOXD-AS1 promotes the epithelial to mesenchymal transition of ovarian cancer cells by regulating miR-186-5p and PIK3R3. J Exp Clin Cancer Res. 2019;38(1):110.

23. Ledermann J. PARP inhibitors in ovarian cancer. Ann Oncol. 2016;27:i40-i4.

24. Mirza MR, Monk BJ, Herrstedt J, Oza AM, Mahner S, Redondo A, et al. Niraparib maintenance therapy in platinum-sensitive, recurrent ovarian cancer. N Engl J Med. 2016;375(22):2154-64.

25. Van Driel WJ, Koole SN, Sikorska K, Schagen van Leeuwen JH, Schreuder $\mathrm{HW}$, Hermans $\mathrm{RH}$, et al. Hyperthermic intraperitoneal chemotherapy in ovarian cancer. N Engl J Med. 2018:378(3):230-40.

26. Januchowski R, Sterzyńska K, Zawierucha P, Ruciński M, Świerczewska M, Partyka M, et al. Microarray-based detection and expression analysis of new genes associated with drug resistance in ovarian cancer cell lines. Oncotarget. 2017;8(30):49944.

27. Liu X, Gao Y, Zhao B, Li X, Lu Y, Zhang J, et al. Discovery of microarrayidentified genes associated with ovarian cancer progression. Int J Oncol. 2015:46(6):2467-78.

28. Babahosseini H, Roberts PC, Schmelz EM, Agah M. Bioactive sphingolipid metabolites modulate ovarian cancer cell structural mechanics. Integr Biol. 2013;5(11):1385-92.

29. Gordon AN, Finkler N, Edwards R, Garcia A, Crozier M, Irwin D, et al. Efficacy and safety of erlotinib $\mathrm{HCl}$, an epidermal growth factor receptor (HER1/ EGFR) tyrosine kinase inhibitor, in patients with advanced ovarian carcinoma: results from a phase II multicenter study. Int J Gynecol Cancer. 2005;15(5):785-92.

30. Bitler BG, Nicodemus JP, Li H, Cai Q, Wu H, Hua X, et al. Wnt5a suppresses epithelial ovarian cancer by promoting cellular senescence. Cancer Res. 2011;71(19):6184-94

31. Mabuchi S, Kuroda H, Takahashi R, Sasano T. The PI3K/AKT/mTOR pathway as a therapeutic target in ovarian cancer. Gynecol Oncol. 2015;137(1):173-9.

32. Tania M, Khan M, Song Y. Association of lipid metabolism with ovarian cancer. Curr Oncol. 2010;17(5):6-11.

33. Gupta M, Babic A, Beck AH, Terry K. TNF-a expression, risk factors, and inflammatory exposures in ovarian cancer: evidence for an inflammatory pathway of ovarian carcinogenesis? Hum Pathol. 2016;54:82-91.

34. Madhusudan S, Muthuramalingam SR, Braybrooke JP, Wilner S, Kaur K, Han C, et al. Study of etanercept, a tumor necrosis factor-alpha inhibitor, in recurrent ovarian cancer. J Clin Oncol. 2005:23(25):5950-9.

35. Tsiambas E, Georgiannos SN, Salemis N, Alexopoulou D, Lambropoulou S, Dimo B, et al. Significance of estrogen receptor 1 (ESR-1) gene imbalances in colon and hepatocellular carcinomas based on tissue microarrays analysis. Med Oncol. 2011;28(4):934-40.

36. Imura M, Yamashita S. Cai L-y, Furuta J-i, Wakabayashi M, Yasugi T, et al. methylation and expression analysis of 15 genes and three normallymethylated genes in 13 ovarian cancer cell lines. Cancer Lett. 2006;241(2): 213-20.

37. Giannopoulou L, Mastoraki S, Strati A, Chebouti I, Kasimirbauer S, Lianidou ES. Abstract 5691:ESR1methylation in plasma cfDNA of patients with highgrade serous ovarian cancer. Cancer Res. 2017;77:5691.

38. Wang L, Ma J, Liu F, Yu Q, Chu G, Perkins AC, et al. Expression of MUC1 in primary and metastatic human epithelial ovarian cancer and its therapeutic significance. Gynecol Oncol. 2007;105(3):695-702

39. Keita M, Wang Z-Q, Pelletier J-F, Bachvarova M, Plante M, Gregoire J, et al. Global methylation profiling in serous ovarian cancer is indicative for distinct aberrant DNA methylation signatures associated with tumor aggressiveness and disease progression. Gynecol Oncol. 2013;128(2):356-63.

40. Yabuno A, Matsushita H, Fujieda N, Shintani D, Ogasawara A, Fujiwara K, et al. Serum cytokine arrays reveal different cytokine profiles as prognostic factors for overall survival in patients with ovarian high-grade serous and clear cell carcinoma. Gynecol Oncol. 2017;145:86.

41. Zhao S-F, Zhang X, Zhang X-J, Shi X-Q, Yu Z-J, Kan Q-C. Induction of microRNA-9 mediates cytotoxicity of curcumin against SKOV3 ovarian cancer cells. Asian Pac J Cancer Prev. 2014;15(8):3363-8.

42. Goto T, Takano M, Hirata J, Tsuda $\mathrm{H}$. The involvement of FOXO1 in cytotoxic stress and drug-resistance induced by paclitaxel in ovarian cancers. $\mathrm{Br} J$ Cancer. 2008;98(6):1068.

43. Wang J, Yang H, Li W, Xu H, Yang X, Gan L. Thioredoxin 1 upregulates FOXO1 transcriptional activity in drug resistance in ovarian cancer cells. Biochim Biophys Acta. 2015;1852(3):395-405.

\section{Publisher's Note}

Springer Nature remains neutral with regard to jurisdictional claims in published maps and institutional affiliations.
Ready to submit your research? Choose BMC and benefit from:

- fast, convenient online submission

- thorough peer review by experienced researchers in your field

- rapid publication on acceptance

- support for research data, including large and complex data types

- gold Open Access which fosters wider collaboration and increased citations

- maximum visibility for your research: over $100 \mathrm{M}$ website views per year

At BMC, research is always in progress.

Learn more biomedcentral.com/submissions 